\title{
Optimization of the total annual cost in mixed materials heat exchanger network by detailed equipment design using particle swarm technique
}

\author{
H. Karimi*1, H.A. Danesh-Ashtiani ${ }^{2}$, C. Aghanajafi ${ }^{3}$ \\ ${ }^{1}$ Department of mechanical engineering, Roudsar and Amlash branch, Islamic Azad University, Roudsar, Iran \\ ${ }^{2}$ Department of mechanical engineering, South Tehran Branch, Islamic Azad University, Tehran, Iran \\ ${ }^{3}$ Faculty of Mechanical Engineering, K.N.Toosi University of Technology, Tehran, Iran \\ E-mail: ${ }^{1}$ Habib_karimi63@yahoo.com
}

Received 27 March 2020, Revised 12 August 2020, Accepted 14 August 2020

\begin{abstract}
This paper investigated an optimization model for heat exchanger network by detailed design method for each heat exchanger unit using particle swarm optimization. This technique is used to determine optimum results for total annual cost in the mixed material heat exchanger network which included the capital and energy costs of heat exchangers. Mixed materials used in corrosive flows and included three types of exchangers such as cheap, expensive and mixed. Generally, two methods used to achieve optimum results in mixed materials heat exchanger networks such as total and partial decompositions methods. But, it used an additional method to achieve a global optimum result by detail equipment design. This method is based on decreasing the total annual cost in each heat exchanger. The total annual cost has been reduced by detailed design in each heat exchanger by optimization technique. The case study was used to show the application of the proposed method. It has been reduced $20.7 \%$ compared with initial case in full integration method. The reduction of the total annual cost by detailed design in the partial decomposition method is $12.4 \%$ compared with the full integration method and $5.78 \%$ compared with the total decomposition method.
\end{abstract}

Keywords: heat exchanger network, mixed material, detailed design, Particle swarm optimization

\section{Introduction}

One of the types of heat exchangers is retrofit designs that there is no chance for changing location of each heat exchangers. In synthesis process, the total annual cost reduced by some methods in mixed materials heat exchangers (HEN) such as pinch analysis and mathematical programing. Synthesis process is included three steps such as method of alternative for optimal values, mathematical formulation and using an optimization method [1]. Gundersen et al. [2] and Furman et al. [3] had studied synthesis process in HEN. As mentioned, pinch analysis is one of the most important methods in HEN that is improved by Grossmann et al. [4] that they studied on HEN synthesis by mathematical programing method. Some researchers studied the total annual cost in HEN by optimizing the variables design such as Bjork and Westerlund [5]. They studied synthesis of HEN that achieved optimized utility costs and heat exchanger areas by optimal configuration. When used mixed materials heat exchanger network, there are two types streams in HEN such as corrosive flow and non-corrosive flow. Therefore, there are three types heat exchanger units in HEN such as cheap, expensive and mixed [6]. One of the types heat exchangers is shell and tube heat exchanger (STHE) that corrosive and non-corrosive flows are in shell or tube sides of these heat exchangers.. For example, tube side made with anti-corrosion materials such as titanium if flow is corrosive in tube side and shell side made with typical materials such as carbon steel if flow is non-corrosive in shell side. Therefore, the cheap type of heat exchanger is between two anti-corrosion streams, the expensive type is between two corrosion streams and the mixed type is between corrosion and anti-corrosion streams
[6]. Hall et al. [7] studied about a mixed heat exchanger network for minimizing total annual costs. They used a correction factor for decreasing the heat exchanger areas. The total annual cost is sum of the operation and capital costs. . Capital cost is depends on various parameters such as installation, material and exponent factors where installation and exponent factors are constant for HEN and mixed materials HEN, but material factor is different in HEN and mixed materials HEN [6]. The cost of mixed type is more than cheap and expensive types heat exchangers due to sealing and technical operation in mixed materials heat exchanger. Some researches divided mixed materials HEN to two subsystems. One of the subsystems is expensive heat exchanger and another is cheap heat exchangers and deleting mixed material heat exchanger $[6,8]$. As mentioned, one of the methods of optimization is to achieve the optimum the total annual cost for each heat exchangers in HEN. Therefore, kern method is used for design of shell and tube heat exchangers. According to figure 1, optimizing each heat exchanger units assisted to closer to global optimum.

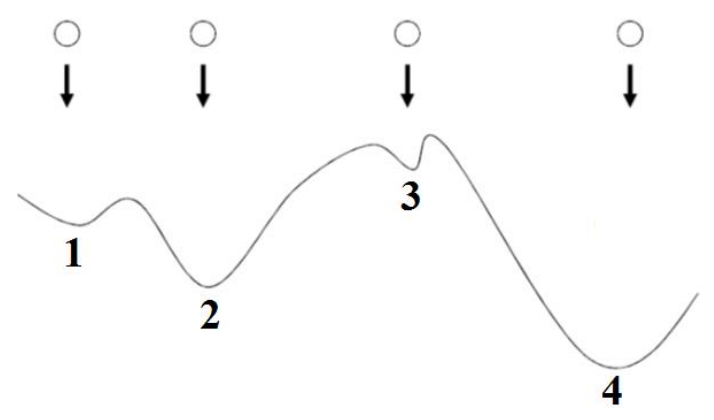

Figure 1. Local and global optimum points 
As seen in figure1, Points 1, 2 and 3 are local optimum points that it's got by traditional mathematical methods and Point 4 is the best global optimum point. This difference is using pinch analysis in study of HEN. However, using pinch analysis led to near to point 4 , but, optimization of each heat exchanger unit is one of the methods that caused to closer to the best global optimum point. Many researchers optimized the total annual cost in the shell and tube heat exchanger. Patel et al. [9], Selbas et al. [10] and Caputo et al. [11] optimized the total annual cost in shell and tube heat exchangers by optimization algorithms such as particle swarm optimization (PSO) and genetic algorithm (GA). They used three design parameters such as spacing of baffles, inside and outside tube diameters as optimization variables. Some researchers used multi-objective approach to optimize the total annual cost [12]. Ozkol et al. [13] studied the geometry of the heat exchanger body to decrease the total annual cost by genetic algorithm. Other optimization algorithms used to optimum the total annual cost of STHEs such as Differential Evaluation (DE), Firefly algorithm (FFA), Biogeography based optimization (BBO) and Independent Component Analysis (ICA) by researchers. Most of the previous research were considered the total annual cost as objective function and spacing of baffles, inside and outside tube diameters as variable parameters. Ravagnani et al [14] studied a heat exchanger network synthesis Based on optimization of detailed equipment on each heat exchanger unit. They used mixed integer nonlinear programming (MINLP) to optimum geometry properties and achieved the best the total annual cost. Ravagnani et al [1] optimized a HEN based on pinch analysis and then by detailed designed of each heat exchanger in HEN, achieved the maximum energy recovery. They used Bell-Delaware method for the formulation of detailed design in each heat exchanger. Ponce-Ortega et al. [15] studied a HEN synthesis based on optimization of detailed heat exchanger design by genetic algorithm. However, some researchers reduced the total annual cost using nanofluids [16]. Karimi et al. [6] minimized the total annual cost in the mixed material heat exchanger. They used kern method to consider pressure drop and heat transfer coefficient in shell and tube sides. However, they used three optimization techniques such as Genetic-particle swarm optimization (GA-PSO) and shuffled frog leaping algorithm (SFLA) to reduce the total annual cost. In another research, Karimi et al. [8] studied about a mixed materials heat exchangers networks. They used two methods for reducing the total annual cost such as total and partial decomposition. In these methods, heat exchanger network divided to two separated subsystems including corrosive and anti-corrosive flows and investigated separately. The total annual cost is decreased using the partial decomposition more than another one.

In this research, the total annual cost of mixed material heat exchanger network reduced by detailed equipment design in each heat exchanger units in by particle swarm optimization technique. This approach is based on optimization of physical and geometrical properties on each heat exchanger units on mixed material heat exchanger networks. The main aims of this study are (i) to optimize the each geometrical parameters on heat exchanger, (ii) to represent the effectiveness of optimization algorithm in the design optimization of HEN from an economic point of view, then, the total annual cost is as objective function. Spacing of baffles, inside and outside tube diameters are as decision variables. The present study considers the optimization of objective function using optimization method, for improving the understanding of optimization of heat exchangers on the HEN. Kern method used for obtaining heat transfer coefficients and the shell-side pressure drops in exchanger units. Results showed remarkable changes compared with others.

\section{Mathematical method}

The equation of design of shell and tube heat exchanger and mixed materials heat exchanger network are based on kern method [8] and cost low formulation [7] respectively. Hall [7] suggested equation of capital costs for mixed materials heat exchanger as follows

$$
\text { Cost of exchanger }=a+b A^{c}
$$

Where A is area of HEN and a,b and c are constant coefficients whereas $b$ coefficient is depended on material factor and its different for types of heat exchanger units such as cheap, expensive and mixed in HEN. The total annual cost for shell and tube heat exchanger unit $C_{t o t}$ determined based on Eq. (2) which $C_{i}$ is capital cost and $C_{o d}$ is the total discounted operating cost as estimated by Caputo et al. [11]. The total annual cost is achieved based on all of the effective parameters in the design of heat exchanger unit.

$$
C_{t o t}=C_{i}+C_{o d}
$$

Further details about the applied equations can be found in Karimi [6] and [8].

\section{Particle swarm optimization (PSO) technique}

Kennedy [17] improved a method based on particle crowd that called particle swarm optimization (PSO). In this method, with selection a random solution is started and by searching form crowd leads to find a best solution [18]. This method based on social systems such as birds. New term of velocity of the particles achieved follows base on ' $\mathrm{pBest}$ ' (best solution) and 'gBest' (best location so far by any particle in the population) locations:

$$
\begin{aligned}
& V_{i+1}=w V_{i}+c_{1} r_{1}\left(p \text { Best }_{i}-X_{i}\right) \\
& +c_{2} r_{2}\left(g \text { Best }_{i}-X_{i}\right) \\
& X_{i+1}=X_{i}+V_{i+1}
\end{aligned}
$$

Where $\mathrm{w}, \mathrm{c}$ and $\mathrm{r}$ are constant values. $\mathrm{V}$ and $\mathrm{X}$ are velocity and location of particles that achieved by the algorithm. Further details about the PSO can be found [18].

\section{Results}

In this work, the total annual cost $C_{\text {tot }}$ has been defined as the objective function. As mentioned, for obtaining the optimization of the total annual cost in HEN, each heat exchanger units is optimized by PSO algorithms. Tables 1 and 2 show economic data and stream data including cost law for different types of materials heat exchanger respectively [19]. Karimi et al. [8] assumed that streams 3, 4, 6 and 9 are corrosive flows and required titanium (Ti) while others are non-corrosive flows and required carbon-steel (CS). Figure 2 showed a mixed materials heat exchanger network including cheap, expensive and mixed heat exchanger units. The total annual cost of mixed material HEN determined 3,747,113 $\$$ for figure 2 [8]. As mentioned, for optimization of detailed equipment, need to all of the parameters for design of shell and tube heat 
exchanger unit and used methanol in shell side as noncorrosive flow and sea water in tube side as corrosive flow.

Table 1. Economic data for mixed material shell and tube heat exchanger cost laws [19]

\begin{tabular}{cc}
\hline Materials of construction & Cost law \\
\hline Carbon-Steel $(\mathrm{CS})$ & $\operatorname{cost}(\$)=30800+750 A^{0.81}$ \\
Stainless-Steel $(\mathrm{SS})$ & $\operatorname{cost}(\$)=30800+1644 A^{0.81}$ \\
$\mathrm{CS} / \mathrm{SS}$ or SS/CS & $\operatorname{cost}(\$)=30800+1339 A^{0.81}$ \\
titanium $(\mathrm{Ti})$ & $\cos t(\$)=30800+4407 A^{0.81}$ \\
$\mathrm{CS} / \mathrm{Ti}$ or Ti/CS & $\operatorname{cost}(\$)=30800+3349 A^{0.81}$ \\
$\mathrm{SS} / \mathrm{Ti}$ or Ti/SS & $\operatorname{cost}(\$)=30800+3749 A^{0.81}$ \\
\hline
\end{tabular}

Table 2. Streams and utility data [8]

\begin{tabular}{ccccc}
\hline Streams & \multicolumn{2}{c}{ Temperature $(\mathrm{C})$} & $\begin{array}{c}\text { Heat } \\
\text { capacity } \\
\text { flow rate } \\
(\text { KW/C) }\end{array}$ & $\begin{array}{c}\text { h-value } \\
(K W / \\
\left.m^{2} C\right)\end{array}$ \\
\hline 1-Hot & Supply & Target & 50 & 0.5 \\
2-Hot & 80 & 65 & 300 & 0.25 \\
3-Hot & 135 & 50 & 290 & 0.3 \\
4-Hot & 220 & 95 & 20 & 0.18 \\
5-Hot & 135 & 105 & 260 & 0.25 \\
6-cold & 65 & 90 & 150 & 0.27 \\
7-cold & 75 & 200 & 140 & 0.25 \\
8-cold & 30 & 210 & 100 & 0.15 \\
9-cold & 60 & 140 & 50 & 0.45 \\
Steam & 250 & -- & -- & 0.35 \\
Cooling & 15 & -- & -- & 0.2 \\
water & 15 & & & \\
\hline
\end{tabular}

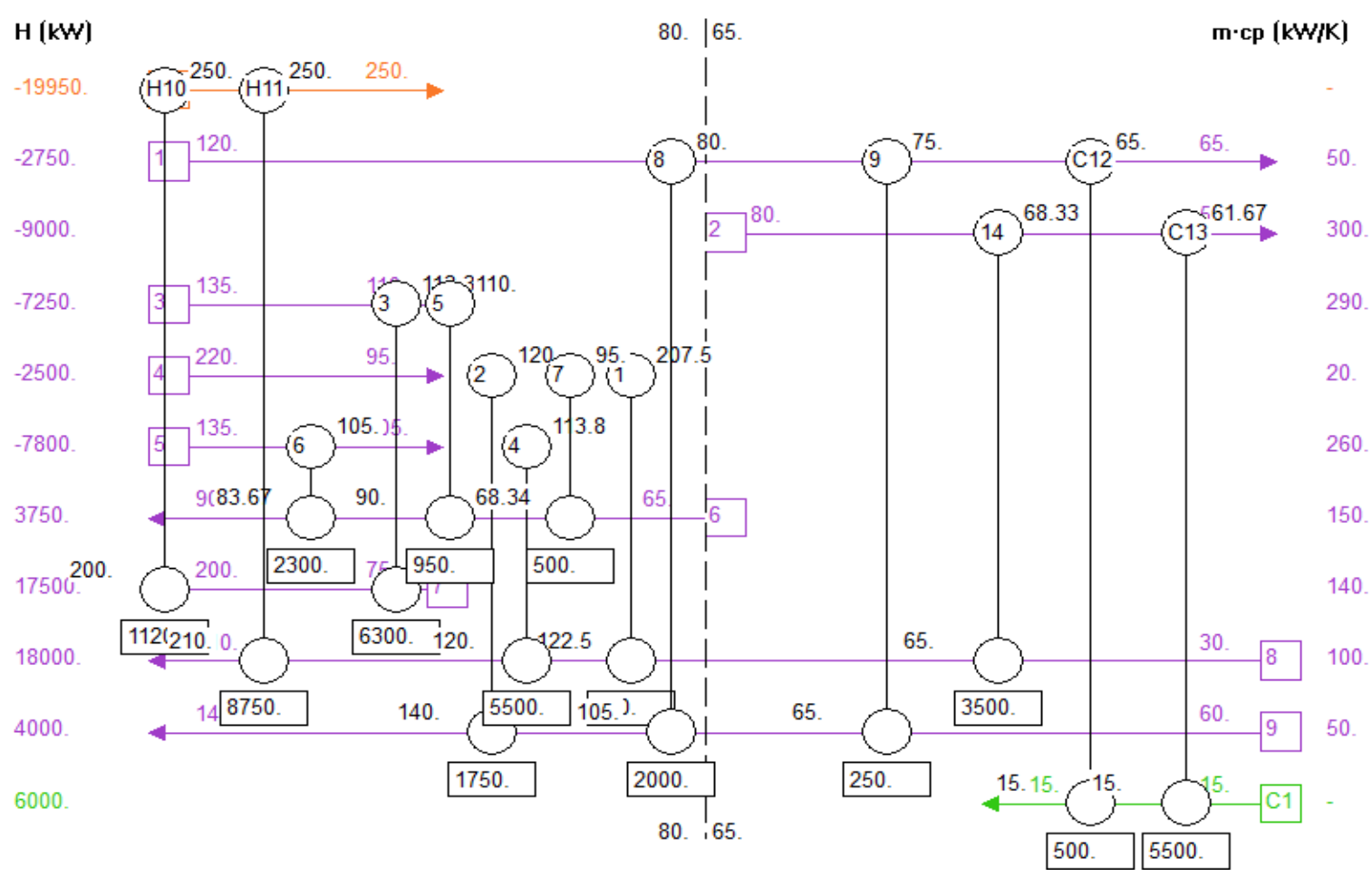

Figure 2. Full integration of mixed materials of construction [8]

Table 3. Process input data and physical properties for case study [11]

\begin{tabular}{|c|c|c|c|c|c|c|c|c|c|}
\hline & $m \cdot\left(\frac{k g}{s}\right)$ & $T_{i}\left({ }^{o} C\right)$ & $T_{o}\left({ }^{o} C\right)$ & $\rho\left(\frac{k g}{m^{3}}\right)$ & $C_{P}\left(\frac{J}{k g}\right)$ & $\mu(P a s)$ & $k\left(\frac{W}{m k}\right)$ & $R_{f}\left(\frac{m^{2} k}{W}\right)$ & $\mu_{w}(P a s)$ \\
\hline $\begin{array}{c}\text { Case } 1 \\
\text { Shell side: methanol } \\
\text { Tube side: sea water }\end{array}$ & $\begin{array}{l}27.8 \\
68.9\end{array}$ & $\begin{array}{l}95 \\
25\end{array}$ & $\begin{array}{l}40 \\
40\end{array}$ & $\begin{array}{l}750 \\
995\end{array}$ & $\begin{array}{l}2840 \\
4200\end{array}$ & $\begin{array}{c}0.00034 \\
0.0008\end{array}$ & $\begin{array}{l}0.19 \\
0.59\end{array}$ & $\begin{array}{c}0.00033 \\
0.0002\end{array}$ & $\begin{array}{l}0.00038 \\
0.00052\end{array}$ \\
\hline
\end{tabular}

Table 3 demonstrated physical properties of case study [8]. It assumed that flow in shell side is non-corrosive and flow in tube side is corrosive. Table 4 demonstrated physical properties on shell and tube sides according to case study on table 3. Value of discounted operating cost is calculated with ny $=10 \mathrm{yr}$, annual discount rate $\mathrm{i}=10 \%$, energy cost $\mathrm{Ce}$ $=0.12 \mathrm{~V} / \mathrm{kW} \mathrm{h}$ and work hours annual $\mathrm{H}=7000 \mathrm{yr} / \mathrm{h}[6]$. Table 5 demonstrated types of flows in shell side and tube side in shell and tube heat exchanger. In table 5, value of heat transfer and type of heat exchanger unit have been marked in bracket. However, all of the physical parameters is specified in shell and tube sides.

Table 4. Bounds for design parameters [6]

\begin{tabular}{ccc}
\hline Parameters & Lower value & Upper value \\
\hline Tubes outside diameters $(\mathrm{m})$ & 0.01 & 0.051 \\
Shell diameters $(\mathrm{m})$ & 0.1 & 1.5 \\
Central baffle spacing $(\mathrm{m})$ & 0.05 & 0.5 \\
\hline
\end{tabular}


Table 5. Physical properties on shell and tube sides

\begin{tabular}{|c|c|c|c|c|c|c|c|c|c|}
\hline $\begin{array}{l}\text { Case } 1 \\
\text { Shell side: methanol } \\
\text { Tube side: sea water }\end{array}$ & $m \cdot\left(\frac{k g}{s}\right)$ & $T_{i}\left({ }^{o} C\right)$ & $T_{o}\left({ }^{o} C\right)$ & $\rho\left(\frac{k g}{m^{3}}\right)$ & $C_{P}\left(\frac{J}{k g}\right)$ & $\mu(P a s)$ & $k\left(\frac{W}{m k}\right)$ & $R_{f}\left(\frac{m^{2} k}{W}\right)$ & $\mu_{w}(\operatorname{Pas})$ \\
\hline \multirow{2}{*}{ E1 (250, exp.) } & 68.9 & 120 & 122.5 & 995 & 4200 & 0.0008 & 0.59 & 0.0002 & 0.00052 \\
\hline & 68.9 & 220 & 207.5 & 995 & 4200 & 0.0008 & 0.59 & 0.0002 & 0.00052 \\
\hline \multirow{2}{*}{ E2 (1750, exp.) } & 68.9 & 207.5 & 120 & 995 & 4200 & 0.0008 & 0.59 & 0.0002 & 0.00052 \\
\hline & 68.9 & 105 & 140 & 995 & 4200 & 0.0008 & 0.59 & 0.0002 & 0.00052 \\
\hline \multirow{2}{*}{ E3 $(6300$, mixed $)$} & 27.8 & 135 & 113.27 & 750 & 2840 & 0.00034 & 0.19 & 0.00033 & 0.00038 \\
\hline & 68.9 & 75 & 120 & 995 & 4200 & 0.0008 & 0.59 & 0.0002 & 0.00052 \\
\hline \multirow{2}{*}{ E4 $(5500$, cheap) } & 27.8 & 135 & 113.84 & 750 & 2840 & 0.00034 & 0.19 & 0.00033 & 0.00038 \\
\hline & 27.8 & 65 & 120 & 750 & 2840 & 0.00034 & 0.19 & 0.00033 & 0.00038 \\
\hline \multirow{2}{*}{ E5 (950, exp.) } & 68.9 & 113.27 & 110 & 995 & 4200 & 0.0008 & 0.59 & 0.0002 & 0.00052 \\
\hline & 68.9 & 83.67 & 90 & 995 & 4200 & 0.0008 & 0.59 & 0.0002 & 0.00052 \\
\hline \multirow{2}{*}{ E6 $(2300$, mixed $)$} & 27.8 & 113.8 & 105 & 750 & 2840 & 0.00034 & 0.19 & 0.00033 & 0.00038 \\
\hline & 68.9 & 68.33 & 83.67 & 995 & 4200 & 0.0008 & 0.59 & 0.0002 & 0.00052 \\
\hline \multirow{2}{*}{ E7 (500, exp.) } & 68.9 & 120 & 95 & 995 & 4200 & 0.0008 & 0.59 & 0.0002 & 0.00052 \\
\hline & 68.9 & 65.01 & 68.34 & 995 & 4200 & 0.0008 & 0.59 & 0.0002 & 0.00052 \\
\hline \multirow{2}{*}{ E8 (2000, mixed) } & 27.8 & 120 & 80 & 750 & 2840 & 0.00034 & 0.19 & 0.00033 & 0.00038 \\
\hline & 68.9 & 65 & 105 & 995 & 4200 & 0.0008 & 0.59 & 0.0002 & 0.00052 \\
\hline \multirow{2}{*}{ E9 $(250$, mixed $)$} & 27.8 & 80 & 75 & 750 & 2840 & 0.00034 & 0.19 & 0.00033 & 0.00038 \\
\hline & 68.9 & 60 & 65 & 995 & 4200 & 0.0008 & 0.59 & 0.0002 & 0.00052 \\
\hline \multirow{2}{*}{ E14 ( 3500, cheap) } & 27.8 & 80 & 68.34 & 750 & 2840 & 0.00034 & 0.19 & 0.00033 & 0.00038 \\
\hline & 27.8 & 30 & 65 & 750 & 2840 & 0.00034 & 0.19 & 0.00033 & 0.00038 \\
\hline
\end{tabular}

Table 6. Optimum values on each heat exchanger units in full integration method HEN

\begin{tabular}{|c|c|c|c|c|c|c|c|}
\hline $\begin{array}{l}\text { Full integration } \\
\text { method }\end{array}$ & $\begin{array}{l}\text { Heat } \\
\text { Duty }\end{array}$ & Opt. do & Opt. Ds & Opt. B & $\begin{array}{c}\text { Opt. } \\
\text { capital cost }\end{array}$ & Capital Cost [8] & Utility Cost \\
\hline E1 & 250 & 0.015007 & 0.82097 & 0.49791 & 41,092 & $79,218.9$ & \\
\hline $\mathrm{E} 2$ & 1750 & 0.015144 & 0.67687 & 0.49629 & 129,730 & 583,968 & \\
\hline E3 & 6300 & 0.015022 & 0.60397 & 0.49983 & 488,430 & $1,520,520$ & \\
\hline E4 & 5500 & 0.015102 & 0.56751 & 0.4993 & 176,850 & 391,351 & \\
\hline E5 & 950 & 0.015068 & 0.65005 & 0.49833 & 110,760 & 441,344 & \\
\hline E6 & 2300 & 0.015005 & 0.61556 & 0.44606 & 143,050 & 571,315 & \\
\hline E7 & 500 & 0.015015 & 0.70017 & 0.49729 & 63,942 & 238,239 & \\
\hline E8 & 2000 & 0.015006 & 0.60849 & 0.47733 & 206,400 & 596,784 & \\
\hline E9 & 250 & 0.015004 & 0.68748 & 0.37483 & 64926 & 135827 & \\
\hline E14 & 3500 & 0.015064 & 0.55872 & 0.49925 & 117,650 & 311333 & \\
\hline $\mathrm{H} 10$ & 11200 & --- & --- & --- & --- & 219,031 & \multirow{2}{*}{$2,394,000$} \\
\hline H11 & 8750 & --- & --- & --- & --- & 249,514 & \\
\hline C12 & 500 & --- & --- & --- & --- & $52,528.8$ & \multirow{2}{*}{60,000} \\
\hline $\mathrm{C} 13$ & 5500 & --- & --- & --- & --- & 231,259 & \\
\hline Sum & & --- & --- & --- & --- & $5,622,231$ & $2,454,000$ \\
\hline T.A.C $[8]$ & & & \multicolumn{5}{|c|}{$5,622,231 \times 0.23+2,454,000=3,747,113 \$$} \\
\hline T.A.C(opt) & & & \multicolumn{5}{|c|}{$2,242,634 \times 0.23+2,454,000=2,969,805 \$$} \\
\hline
\end{tabular}

Table 6 showed the optimum value of decision variables including capital cost of each heat exchanger units and the total annual cost (TAC) in full integration method of HEN by the PSO algorithm. As seen, most of the values reduced. The total annual cost is achieved 2,969,80 $\$$ for ten years that its $20.7 \%$ less than compared with Ref. [8] that annualization factor was calculated 0.23 based on Ref. [8]. There are no optimization for coolers and heaters in this study. As seen, the total annual cost has been decreased by optimization of detailed design for each heat exchanger unit. Therefore it's got closer to global optimum, however is not yet a global optimum. Using total decomposition method, HEN divided to two sub-networks including network with corrosive flow such as carbon steel and non-corrosive flow such as titanium. As mentioned, the network by made of carbon steel is the cheap network and the network by made of titanium is the expensive network. Figure 3 demonstrated heat exchanger network in two subsystems including expensive and cheap networks which contained titanium and carbon steel materials respectively. Table 7 showed the optimum value of decision variables, capital cost of each heat exchanger units and the total annual cost (TAC) in mixed material HEN by the PSO algorithm in total decomposition method. The total annual cost is achieved 3,195,019 \$ for ten years that its $9.21 \%$ less than compared with Ref. [8] that annualization factor was calculated 0.23 based on Ref. [8]. As seen, the optimum the total annual cost in total decomposition method (Figure 3) is $7.58 \%$ more than the optimum the total annual cost in full integration method (Figure 2). It's demonstrated that total decomposition method isn't useful in this method (detailed equipment design). Using decomposition methods such as total and partial aren't always useful and depended on how layout of the heat exchanger in HEN and physical properties of flows in HEN. Using detailed design of heat exchangers units method, total decomposition method is not suitable for decreasing the total annual cost. Another method of reduction the total annual cost in HEN is partial decomposition method. Table 8 showed the total annual cost by partial decomposition method and the optimum results by detailed design method by PSO algorithm. In partial decomposition method, at least one mixed material of heat exchanger was used to reduce the total annual cost [8]. The results showed the optimum total annual cost is $16.1 \%$ less 
than the results of Ref. [8], as well as, its $5.78 \%$ and $12.4 \%$ less than the optimum total annual cost in full integration and total decomposition methods, respectively. However, results showed that used of partial decomposition method led to decrease in the total annual cost.

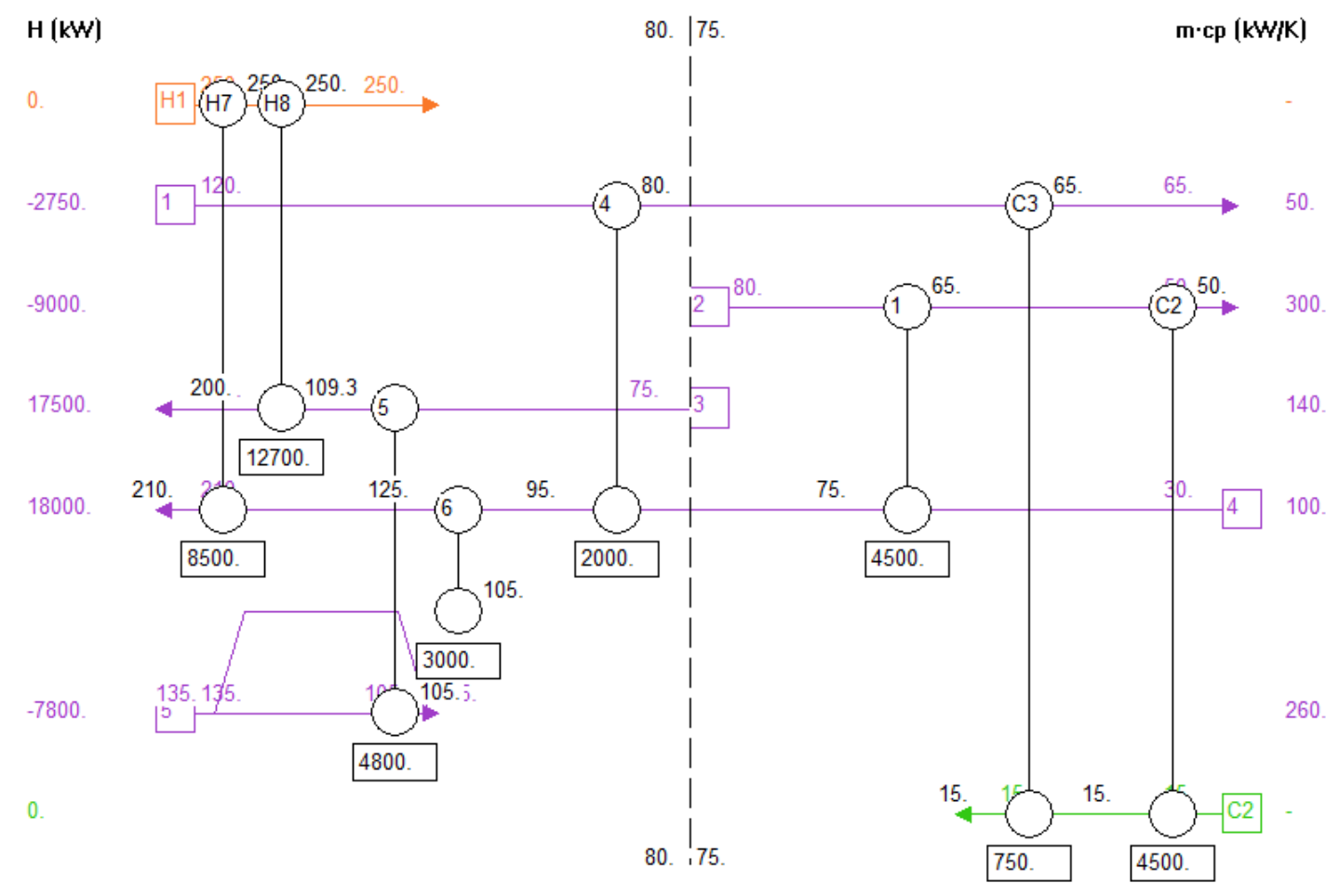

a) cheap network

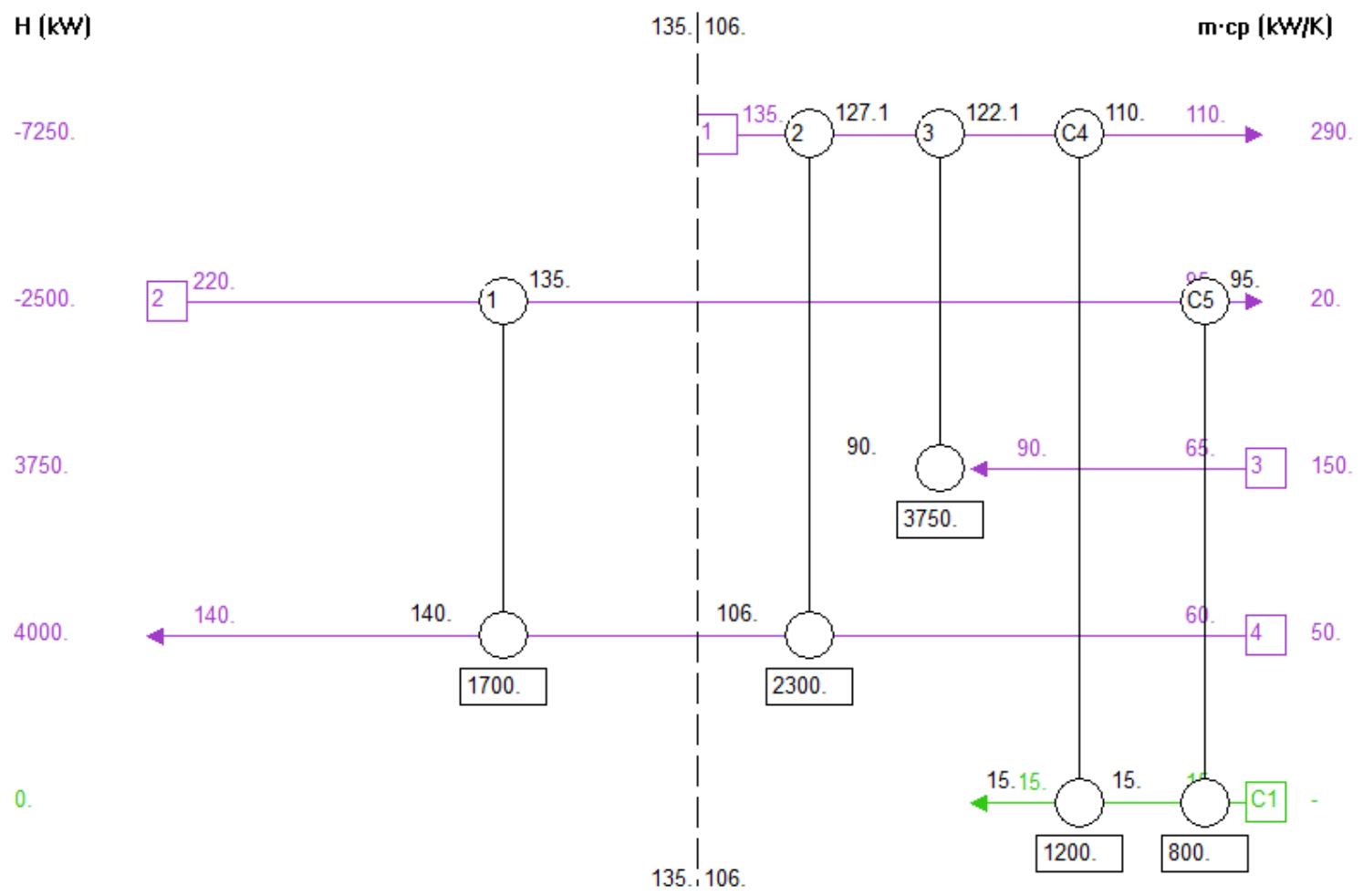

b) expensive network

Figure 3.Total decomposition of mixed materials of construction [8]

Table 7. Optimum values on each heat exchanger units in Total decomposition method HEN a). for expensive network 


\begin{tabular}{|c|c|c|c|c|c|c|c|}
\hline Total Dec. & Heat Duty & do & Ds & $\mathrm{B}$ & Opt. cost & Capital Cost & Utility Cost \\
\hline E1 & 1700 & 0.015023 & 0.66113 & 0.49975 & 121780 & 432,972 & \multirow{7}{*}{20,000} \\
\hline E2 & 2300 & 0.015003 & 0.65729 & 0.49687 & 130360 & 455,533 & \\
\hline E3 & 3750 & 0.015013 & 0.65758 & 0.49774 & 177570 & 782,385 & \\
\hline $\mathrm{C} 4$ & 1200 & -- & -- & -- & -- & 219,018 & \\
\hline $\mathrm{C} 5$ & 800 & -- & -- & -- & -- & 192,772 & \\
\hline total & & & & & & $2,082,680$ & \\
\hline T.A.C & \multirow{2}{*}{\multicolumn{7}{|c|}{$\frac{2,082,680 \times 0.23+20,000=499,016 \$}{\text { b). for cheap network }}$}} \\
\hline & & & & & & & \\
\hline & Heat Duty & do & Ds & $\mathrm{B}$ & Opt. cost & Capital Cost & Utility Cost \\
\hline E1 & 4500 & 0.01509 & 0.58452 & 0.49795 & 398,510 & 348,624 & \multirow{6}{*}{52,500} \\
\hline $\mathrm{C} 1$ & 4500 . & & & & & 226597 & \\
\hline $\mathrm{C} 2$ & 750. & & & & & $59,978.9$ & \\
\hline E2 & 2000 & 0.015019 & 0.5829 & 0.49667 & 216,600 & 172,098 & \\
\hline E3 & 4800 & 0.015184 & 0.57307 & 0.49952 & 152,900 & 293,020 & \\
\hline E4 & 3000 & 0.015047 & 0.58259 & 0.49885 & 291,810 & 355,762 & \\
\hline H1 & 8500 & -- & -- & -- & -- & 155811 & \multirow[t]{2}{*}{$2,544,000$} \\
\hline $\mathrm{H} 2$ & 12700 & -- & -- & -- & -- & 231572 & \\
\hline Sum & & & & & & $1,843,462$ & \\
\hline T.A.C [8] & \multicolumn{7}{|c|}{$1,843,462 \times 0.23+2,544,000+52,500=3,020,496 \$$} \\
\hline $\begin{array}{l}\text { T.A.C } \\
\text { (opt.) }\end{array}$ & \multicolumn{7}{|c|}{$2,981,474+213,545=3,195,019 \$$} \\
\hline
\end{tabular}

Table 8. Optimum values on each heat exchanger units in Partial decomposition method HEN

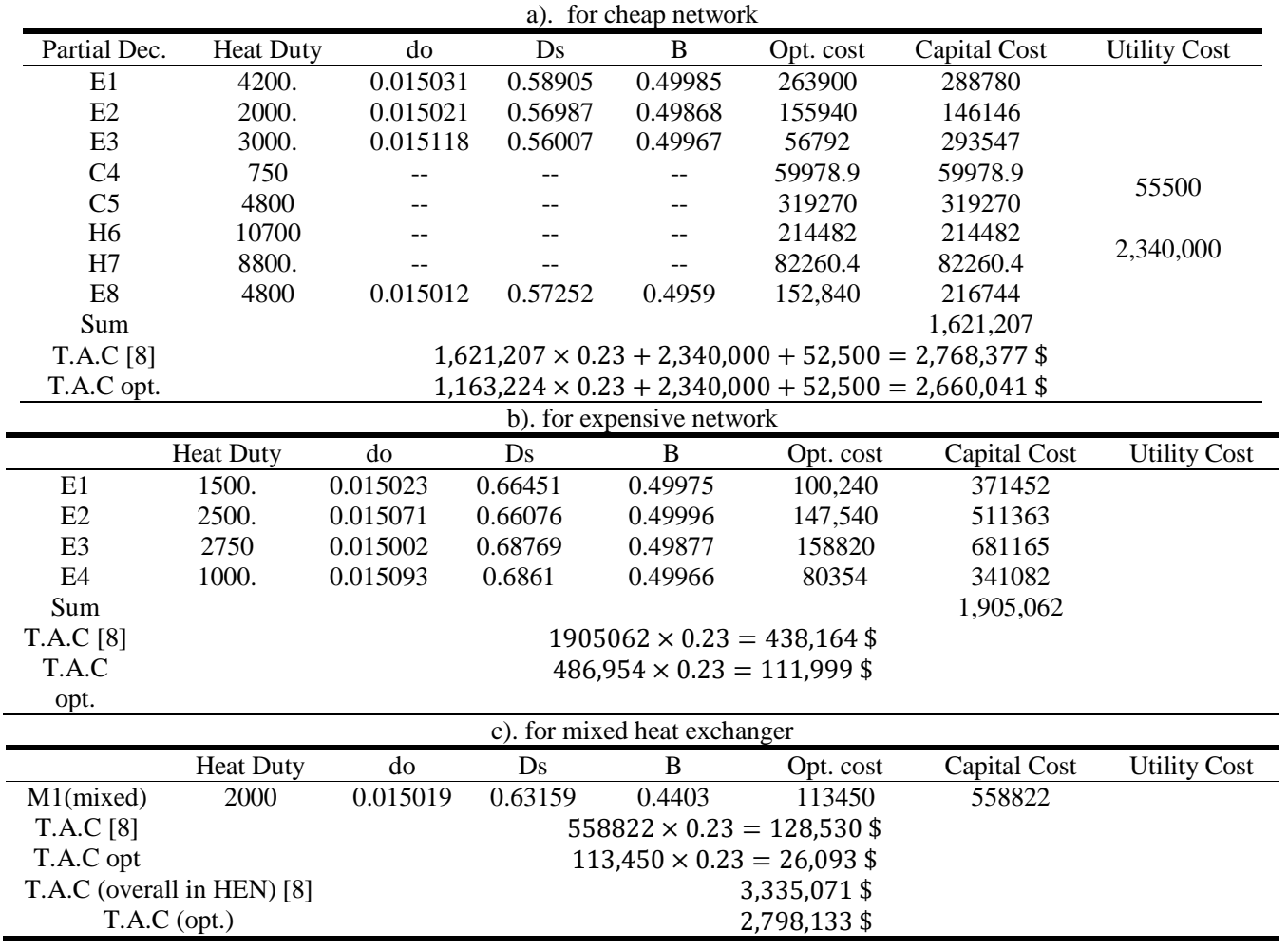

\section{Conclusion}

The optimization of the total annual cost in mixed material heat exchangers studied by detailed design of each heat exchanger units by PSO algorithm. Its used shell and tube heat exchanger units in HEN. The total annual cost is as objective function. There are three decision variable for processes of optimization such as tube outer diameter, shell diameter and central baffle spacing. Mixed materials heat exchangers network are included two flows including corrosive and non-corrosive flows. There are three type of heat exchangers in HEN such as cheap, expensive and mixed. The mixed type of heat exchanger has been used carbon steel for non-corrosive flow in shell side and titanium for corrosive flow in tube side. However, HEN divided in two subnetwork total decomposition method and partial decomposition method. Detailed design method led to reduce the total annual cost in mixed material heat exchanger network by full integration and partial decomposition methods. It has been reduced $20.7 \%$ compared with initial case in full integration method. Also, there are $9.21 \%$ and $16.1 \%$ to reduce compared with initial cases in total and partial decomposition methods. However, the reduction of the total annual cost by detailed design in partial decomposition method is $12.4 \%$ compared with full integration method and $5.78 \%$ compared with total decomposition method. The reduction of the total annual cost by detailed design in total decomposition method is $-7.61 \%$ compared with full integration method. Based on the findings of this study, using of detailed design of heat exchangers by optimization algorithms led to more reduction in the total annual cost especially in mixed material heat exchanger networks. Moreover, this study obtained target the total annual cost of the heat exchanger network using PSO optimization technique.

\section{References:}

[1].Marzbanrad, J., Sharifzadegan, A. and Kahrobaeian, A. 
"Thermodynamic Optimization of GSHPS Heat Exchangers" International Journal of Thermodynamics, Volume 10, Issue 3, pp. 107 - 112, 2007.

[2]. Gundersen, T., Naess, L. "The synthesis of cost optimal heat exchanger networks-an industrial review of the state of the art" Computers and Chemical Engineering, 12(6), pp. 503-530, 1998.

[3]. Furman, K., Sahinidis, N. "Critical Review and Annotated Bibliography for Heat Exchanger Network Synthesis in the 20th Century" Industrial \& Engineering Chemistry Research, 41(10), pp. 2335-2370, 2002.

[4]. Grossmann, I., Caballero, J., Yeomans, H. “Advances in mathematical programming for the synthesis of process systems" Latin American Applied Research, 30(4), pp. 263-284, 2000.

[5]. Bjork, K. and Westerlund, T. "Global optimization of heat exchanger network synthesis problems with and without the isothermal mixing assumption" Computers and Chemical Engineering, 26, pp.1581-1593, 2002.

[6]. Karimi, H., Danesh Ashtiani, H.A. and Aghanajafi, C. "Study of mixed materials heat exchanger using optimization techniques", Journal of Engineering, Design and Technology,17(2), pp.414-433, 2019.

[7]. Hall, S.G. and Ahmad, S. "Capital cost targets for heat exchanger networks comprising mixed materials of construction, pressure ratings and exchanger types", Computers Chemical Engineering, Vol. 14 No. 3, pp. 319-335, 1990.

[8]. Karimi H., Ahmadi-Danesh-Ashtiani H, Aghanajafi C. "Applying multiple decomposition methods and optimization techniques for achieving optimal cost in mixed materials heat exchanger networks. International Journal of Energy Research, 43, pp. 3711-3722, 2019.

[9]. Patel, V. and Rao, R. "Design optimization of shell-andtube heat exchanger using particle swarm optimization technique" Applied Thermal Engineering, 30(12), pp. 1417-1425, 2010.

[10]. Selbas, R., Kızılkan, O. and Reppich, M. “A new design approach for shell-and-tube heat exchangers using genetic algorithms from economic point of view" Chemical Engineering Process, Vol. 45, pp. 268-275, 2006.

[11]. Caputo, A., Pelagagge, P. and Salini, P. "Heat exchanger design based on economic optimization" Applied Thermal Engineering, 28(10), pp. 1151-1159, 2008.

[12]. Hilbert, R., Janiga, G., Baron, R. and Thevenin, D. " "Multi-objective shape optimization of a heat exchanger using parallel genetic algorithms", International Journal of Heat and Mass Transfer, 49(16), pp. 2567-2577, 2006.

[13]. Ozkol, I. and Komurgoz, G. "Determination of the optimum geometry of the heat exchanger body via a genetic algorithm", International Journal of Heat and Mass Transfer, 48, pp. 283-296, 2005.

[14]. Ravagnani, M. and Caballero, J. "Optimal heat exchanger network synthesis with the detailed heat transfer equipment design" Computers and Chemical Engineering, 31, pp.1432-1448, 2007.

[15]. Ponco-Otega, J., Serna-González, M. and JiménezGutiérrez, A. "Synthesis of multi pass heat exchanger networks using genetic algorithms" Computers \& Chemical Engineering, (32), 10, pp. 2320-2332, 2008.

[16]. Rajagopal, T., Surana, A., Koppula, J., Harshit, S. and Kumar, U. "Numerical investigation of shell and tube heat exchanger using $\mathrm{Al} 2 \mathrm{O} 3$ nanofluid". International Journal of Thermodynamics, 20, pp.59-68, 2017.

[17]. Kennedy, J. and Eberhart, R. "Particle swarm optimization" Proceedings of the IEEE International Conference on Neural Networks Perth, Australia, 1995, pp.1942-1948.

[18]. Patel, V. and Rao, R. "Design optimization of shelland-tube heat exchanger using particle swarm optimization technique" Applied Thermal Engineering, 30(12), pp. 1417-1425, 2010.

[19]. Taal, M., Bulatov, I., Klemes, J. and Stehlik, P. “Cost estimation and energy price forecast for economic evaluation of retrofit projects" Applied Thermal Engineering, Vol. 23, No. 14, pp. 1819-1835, 2003. 